\section{E-053 TIME IS BRAIN: STANDARDIZING THROMBECTOMY METRICS LEADS TO FASTER RECANALIZATION}

D Frei, D Loy, R Bellon, D Huddle. Neurointerventional Surgery, Radiology Imaging Associates, Denver, CO

\subsection{6/neurintsurg-2016-012589.125}

Background Acute stroke treatment has been proven to be most effective when performed immediately. The objective of our study was to describe the steps taken to improve time metrics for patients receiving intra-arterial therapy (IAT), and compare metrics before and after implementation of interventions.

Hypothesis Through streamlining the evaluation and treatment process of IAT, we predict our times between patient arrival, imaging, puncture and recanalization will be reduced.

Methods On June 1, 2013, we instituted a series of interventions in the interventional radiology suite to streamline care, including requiring the thrombolytic team to meet all transferred patients in the imaging room within 30 minutes of arrival, as well as introducing a wheeled stroke cart replete with a stroke tray containing all devices needed to perform a thrombectomy, standardizing the thrombectomy procedure, switching from general anesthesia to conscious sedation for all stroke patients, and no longer shaving the groin or using a foley catheter. We also added an additional biplane INR room, doubling our room capacity. We compared time metrics of patient arrival to imaging, imaging to puncture, and puncture to recanalization of acute ischemic stroke patients that received IAT before (1/1/12-5/31/13) and after (6/1/13-5/31/ 15) the interventions using univariate analysis.

Results Three hundred twenty-two patients received IAT during the study period. Nearly three quarters (73.3\%) of the population was transferred from a referring facility. There were significantly less female patients in the post-intervention cohort $(59.5 \% \mathrm{v} 48.0 \%, \mathrm{p}=0.04)$; there were no significant differences in age, race, or initial NIHSS. We found statistically significant reductions in time between patient arrival to imaging (19.2 $\pm 9.6 \mathrm{v} 13.6 \pm 6.7, \mathrm{p}<0.000)$, imaging to puncture $(57.9 \pm 36.2$ v $46.9 \pm 40.5, \mathrm{p}=0.04)$, and puncture to recanalization $(70.7 \pm 47.3 \mathrm{v} 53.1 \pm 40.4$, $\mathrm{p}=0.004)$ after implementation of the interventions.

Conclusions Our initiatives allowed us to refine our process of care, resulting in a significant reduction of time between patient arrival and imaging, imaging to puncture, and puncture to recanalization.

Disclosures D. Frei: 1; C; Penumbra, Medtronic, Stryker, MicroVention, Sequent, Siemens, Codman. 2; C; Penumbra, Stryker, MicroVention, Codman, Siemens. 3; C; Penumbra, Stryker, MicroVention, Codman, Siemens. 4; C; Penumbra. D. Loy: None. R. Bellon: None. D. Huddle: None.

\section{E-054 CORRELATION BETWEEN THROMBUS DENSITY AND RECANALIZATION OR STROKE ETIOLOGY IN ACUTE ISCHEMIC STROKE}

${ }^{1} \mathrm{M}$ Jagani, ${ }^{2} \mathrm{~W}$ Brinjikji, ${ }^{2} \mathrm{D}$ Kallmes. 'Mayo Medical School, Rochester, MN; ${ }^{2}$ Radiology, Mayo Clinic, Rochester, MN

\subsection{6/neurintsurg-2016-012589.126}

Background and purpose The hyperdense middle cerebral artery (MCA) sign is a well-established marker of thrombus in the MCA. Studies have suggested that a hyperdense MCA is a common finding when a non-contrast head CT is performed within a few hours of stroke symptoms onset. ${ }^{1}$ The hyperdensity of the basilar artery has also been described in basilar artery occlusions. ${ }^{2}$

Previous studies have correlated recanalization success with thrombus density on non-enhanced CT scans. ${ }^{3,4}$ In our study, we aimed to identify if thrombus density predicted revascularization success or suggested a specific etiology in acute ischemic stroke patients.

Methods and Materials We retrospectively studied 118 patients with acute ischemic stroke that were treated with mechanical thrombectomy devices and/or intravenous tPA from February 2009 to December 2015. The maximum and mean thrombus and normal vessel density was measured in Hounsfield units (HU) on a non-enhanced cranial CT in our institution's proprietary image archiver and viewer. Recanalization was assessed either post-procedurally or upon review by an interventional neuroradiology fellow using the Thrombolysis in Cerebral Infarction (TICI) grading system with successful recanalization defined as TICI $2 \mathrm{~b}-3$. The ratio of clot to normal vessel density was calculated for the maximum and mean HU values. T-tests were used to study the association between clot density and recanalization or etiology. A subgroup of only MCA occlusions was also analyzed.

Results Of the 118 patients (mean age 66; 47\% female), there was no statistically significant difference in mean $(p=0.17)$ or maximum clot density $(p=0.22)$ between the successful and unsuccessful recanalization groups (Table 1). There was also no difference in the mean $(p=0.36)$ or maximum clot $(p=0.22)$ to normal vessel ratio. When comparing densities between the large vessel and cardioembolic etiology, there was no difference in mean or maximum clot density or the clot to vessel ratios. In the subgroup analysis of MCA occlusions, similar findings were noted (Table 2). No difference was found when between the successful and unsuccessful recanalization groups in mean clot density $(\mathrm{p}=0.37)$, max clot density $(p=0.46)$, mean clot to vessel ratio $(p=0.46)$, or max clot to vessel ratio $(\mathrm{p}=0.48)$.

Conclusion In conclusion, our study found no relationship between thrombus attenuation and recanalization success or stroke etiology. While prior studies have suggested that higher attenuation is associated with good recanalization, our study could not find such a link. ${ }^{4}$ More studies are required to identify factors that predict successful recanalization in acute ischemic stroke patients.

\begin{tabular}{|c|c|c|c|}
\hline (mean, SD) & $\begin{array}{l}\text { Successful recanalization } \\
(\mathrm{n}=80)\end{array}$ & $\begin{array}{l}\text { Unsuccessful } \\
\text { recanalization }(n=38)\end{array}$ & $\begin{array}{l}\mathrm{p} \\
\text { value }\end{array}$ \\
\hline $\begin{array}{l}\text { Mean Clot Density } \\
\text { (HU) }\end{array}$ & $50.1(7.4)$ & $53(12.7)$ & 0.17 \\
\hline $\begin{array}{l}\text { Max Clot Density } \\
\text { (HU) }\end{array}$ & $58.1(8.9)$ & $61.4(15.2)$ & 0.22 \\
\hline Mean Ratio & $1.31(0.22)$ & $1.37(0.34)$ & 0.36 \\
\hline Max Ratio & $\begin{array}{l}1.32(0.19) \\
\text { Large Artery }(n=35)\end{array}$ & $\begin{array}{l}1.40(0.39) \\
\text { Cardioembolic }(n=56)\end{array}$ & 0.22 \\
\hline $\begin{array}{l}\text { Mean Clot Density } \\
(\mathrm{HU})\end{array}$ & $51.5(7.7)$ & $49.7(8.5)$ & 0.31 \\
\hline $\begin{array}{l}\text { Max Clot Density } \\
\text { (HU) }\end{array}$ & $60.9(10.1)$ & $57.4(8.6)$ & 0.09 \\
\hline Mean Ratio (HU) & $1.33(0.16)$ & $1.30(0.25)$ & 0.51 \\
\hline Max Ratio (HU) & $1.36(0.16)$ & $1.31(0.22)$ & 0.31 \\
\hline
\end{tabular}

